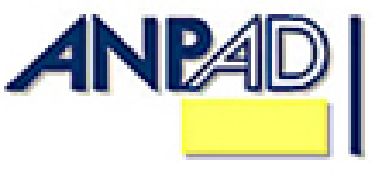

Disponível em

http://www.anpad.org.br/rac

RAC, Rio de Janeiro, v. 17, n. 5, art. 4, pp. 574-597, Set./Out. 2013

(oc) EY-No

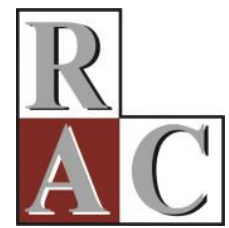

\title{
Dionísio Usa Chilli Beans? - Análise Mitológica da Publicidade da "Marca da Pimenta"
}

\author{
Does Dionysius Wear Chilli Beans? - Mythological Analysis of the "Pepper Brand" \\ Advertising
}

Ildembergue Leite de Souza

E-mail: ildembergue.leite@gmail.com Universidade Federal de Pernambuco - UFPE Av. dos Economistas, s/n, CDU, 50670-901, Recife, PE, Brasil.

André Luiz Maranhão de Souza Leão E-mail: aleao21@hotmail.com Universidade Federal de Pernambuco - DCA/UFPE Av. dos Economistas, s/n, CDU, 50670-901, Recife, PE, Brasil. 


\title{
Resumo
}

Com a crescente ênfase na dimensão simbólica do consumo, as marcas passaram a atuar como canais de autoexpressão e de transformação da cultura e da sociedade, entre outras razões, por produzir e reproduzir mitos. Um dos principais mecanismos utilizados para esse fim é a publicidade. A Chilli Beans se apresenta como uma marca que adota tal premissa. Diante do exposto, esta pesquisa foi norteada pela seguinte questão: Como o mito reproduzido na publicidade da Chilli Beans opera na significação de tal marca? Para tal, associamos a semiologia barthesiana à linguística saussuriana como uma forma de analisar a publicidade impressa desenvolvida pela marca em todo seu histórico de campanhas até então. Os resultados revelam a reprodução de doze mitos que sustentam a metanarrativa que dá significação à marca: o hedonismo.

Palavras-chave: marca; publicidade; mitos; hedonismo; Chilli Beans.

\begin{abstract}
With a growing emphasis on the symbolic dimension of consumption, brands have started to act as channels of self-expression and transformation of culture and society, while producing and reproducing myths. One of the major mechanisms used for this purpose is advertising. Chilli Beans can be presented as a brand that adopts this premise. Therefore, this research was guided by the following question: How do myths reproduced in Chilli Beans's advertising function to give the brand meaning? To this purpose, we used Barthesian Semiology to analyze print advertising developed by the brand along its history. Results reveal a reproduction of twelve myths that sustain the metanarrative that gives meaning to the brand: hedonism.
\end{abstract}

Key words: brand; advertising; myths; hedonism; Chilli Beans. 


\section{Introdução}

Na medida em que o consumo se assumiu como uma verdadeira atividade cultural e, como tal, carregado de toda a complexidade que lhe é inerente, o caráter simbólico se tornou decisivo na escolha de uma marca, entidade com forte carga de significados que ultrapassou a dimensão econômica e hoje ocupa um papel de destaque no meio social (Featherstone, 1995; Slater, 2002). Esse argumento tem ganhado força entre correntes de pensamento, como a Teoria da Cultura de Consumo (Arnould \& Thompson, 2005; Gaião, Souza, \& Leão, 2012), e aponta para a importância de se investigar a cultura como dimensão apta a oferecer o embasamento cultural, histórico e político necessário ao entendimento das marcas em seu contexto (Schroeder, 2009).

As marcas atuam como canais de autoexpressão e assumem um papel na transformação da cultura e da sociedade, processo no qual não só produzem significados, como também recorrem a expressões culturais particulares para provocar tais transformações (Holt, 2005). Diante desse contexto, é forte o argumento de que códigos culturais estão estreitamente ligados ao sentido e ao valor da marca (Schroeder, 2009).

$\mathrm{Na}$ transferência dos significados envolvidos no consumo, ganha relevo a atuação de intermediadores como a publicidade, que promove uma fusão dos produtos anunciados com a representação do mundo culturalmente constituído (Featherstone, 1995; McCracken, 2003; Slater, 2002). Os mitos, trabalhados sobretudo na publicidade, são relevantes para a produção e reprodução daqueles significados que as marcas desejam imprimir na construção de suas identidades. O conceito de mito ${ }^{(1)}$ aqui considerado não é aquele ricamente difundido pela cultura grega e romana, mas sim o de uma narrativa que se origina quando a cultura de modo geral oferece elementos ou valores artificiais e ideológicos, como se fossem indiscutíveis e naturais (Barthes, 2009). A semiologia barthesiana, importante para o estudo dos sistemas de significados, tem se apresentado como uma valiosa ferramenta para compreensão dessa variedade de mitos que compõe a significação das marcas (Sherry \& Camargo, 1987).

Apesar do crescente número de pesquisas alinhadas com a referida perspectiva teórica que reconhece a importância dos significados para as marcas, ainda é incipiente o volume de trabalhos que tratam dessa abordagem no cenário específico brasileiro. Uma marca nacional que se promove muito mais pelo que significa do que por sua utilidade, a Chilli Beans - maior marca latino-americana do segmento de óculos de sol - tem suas campanhas publicitárias majoritariamente pautadas pela invocação simbólica. Além de atender os requisitos necessários para o entendimento do fenômeno a ser estudado, pesou para a escolha da marca a disposição dos gerentes da Chilli Beans em permitir o acesso a informações indispensáveis para a construção do corpus de pesquisa (Bauer \& Aarts, 2008).

Diante do que foi tratado e tomando a Chilli Beans como um caso representativo do fenômeno apresentado, este trabalho ${ }^{(2)}$ se propõe a responder, por meio da semiologia barthesiana, a seguinte questão de pesquisa: Como o mito reproduzido na publicidade da Chilli Beans opera na significação de tal marca?

De forma ampla, a proposta desta investigação é contribuir para a compreensão da marca como um recurso cultural, assim como delinear o papel que os mitos trabalhados na publicidade têm nesse processo. Os resultados encontrados revelam que a marca em estudo tem no hedonismo sua grande narrativa mitológica. Levando em conta a carência de estudos voltados para o contexto do mercado brasileiro, os conhecimentos aqui gerados podem colaborar com a academia, uma vez que incrementam o conhecimento sobre a dimensão simbólica em marcas brasileiras e ratificam a aplicação da semiologia barthesiana para esse tipo de estudo.

O artigo também será útil aos profissionais de marketing e áreas afins, que poderão encontrar nas proposições feitas um reforço da ideia de que a compreensão dos significados se apresenta como um rico norteador dentro do complexo universo do gerenciamento de marcas. No branding, isso é particularmente importante porque a marca que se vale de uma associação mítica tem nas mãos um 
poderoso recurso na disputa pela preferência do consumidor, na medida em que a concorrência não poderá reproduzir facilmente o mito construído em torno de uma marca e estendido aos produtos que essa representa (Holt, 2005).

Como forma de atingir a proposta do artigo, a seção seguinte trata da marca e seu papel na sociedade de hoje. Na terceira parte, a publicidade é abordada a partir de sua importância como cultivadora dos significados e dos mitos tão indispensáveis à construção das marcas. A quarta seção se volta para o mito propriamente, discorrendo a respeito de seu conceito e da estrutura que o sustenta, de acordo com a proposta de Roland Barthes. A seguir, são abordados os procedimentos metodológicos adotados na investigação. A sexta seção traz os resultados obtidos: mitos identificados, evolução e correlação dos mesmos. Em sua última parte, o artigo se debruça sobre as metanarrativas reproduzidas na publicidade da marca e apresenta as considerações finais da pesquisa.

\section{Marca: uma Construção Cultural}

A marca como ideia existe há pelo menos cinco mil anos (Costa, 2008; Neumeier, 2008), entretanto, seu destaque no papel de conquistar uma clientela veio com a Revolução Industrial, período que exigiu a busca de novos mercados, no qual se passou a oferecer produtos embalados e identificados. Se antes identificavam o produto por sua utilidade, hoje as marcas vestem o bem de consumo com uma forte carga simbólica (Featherstone, 1995; Semprini, 2010; Slater, 2002), atuando como verdadeiros canais de autoexpressão através dos quais o consumidor constrói sua identidade. Em tal cenário, a marca assume um valioso papel na transformação da cultura e da sociedade, e, nesse processo, tanto produz significados, como recorre a expressões culturais particulares para provocar tais transformações (Holt, 2005).

De acordo com Slater (2002), os significados envolvidos no processo de consumo são partilhados, formados no interior de culturas e com base nos recursos disponíveis, como valores e hábitos, todos de natureza social. Tais significados podem se encontrar imbricados nas mais variadas instâncias sociais e, para isso, assumem um fluxo ininterrupto que parte do mundo culturalmente construído, passa pelo bem de consumo e, finalmente, atinge o consumidor individual (McCracken, 2003).

A base conceitual dessa nova abordagem se encontra em grande medida na Teoria da Cultura de Consumo (Arnould \& Thompson, 2005), uma perspectiva que configura o consumo como algo continuamente formatado pelas interações que se dão no interior de um contexto sociocultural dinâmico, e dedicam especial atenção para os fatores que moldam as experiências e as identidades dos consumidores na infinidade de contextos que permeiam seu cotidiano (Brown, 1993; Holt, 1995; Leão $\&$ Mello, 2009; Simmons, 2008).

Não é de hoje que o marketing deixou de considerar o caráter unicamente utilitarista na construção de marcas e passou a considerar também os valores emocionais e simbólicos (e.g., Aaker, 1997; Belk, 1988; Chernatony \& McDonald, 2006), entretanto, a abordagem tradicional, ao prestar pouca atenção à dinâmica social, ainda peca quando considera o consumidor como um indivíduo congelado no tempo e isolado das influências sociais e culturais mais amplas (Nairn, Griffin, \& Wicks, 2008). Diante desse cenário, tem ganhado força o argumento de que códigos culturais - contidos na História, imagens, mitos, etc. - estão estreitamente ligados ao sentido e ao valor da marca, o que aponta para a necessidade de investigar a cultura como uma terceira dimensão em seu estudo (Schroeder, 2009).

Nessa visão, entendemos a marca como um símbolo dialeticamente construído através de processos interativos e complexos de coautoria inseridos dentro de contextos específicos e situados no tempo (Fournier, 1998; Holt, 2002). Assim, é preciso ter em mente que nomes, logotipos e desenhos constituem apenas sinais materiais, que estarão vazios até que a marca construa sua história pela soma 
de ideias e experiências que agrega em torno de si ao longo do tempo (Holt, 2005), e que a construção da mesma, sendo de natureza coletiva (Bengtsson \& Ostberg, 2006; Holt, 2005), exigirá a compreensão de quem são e qual o papel de cada um dos agentes que contribui com sua significação.

\section{A Publicidade como Cultivadora de Mitos}

A publicidade tem uma importante função na transferência de significados na medida em que promove a fusão dos produtos que anuncia com a representação do mundo culturalmente constituído, num processo que se reproduz constantemente e que permite ao consumidor manter-se informado a respeito do universo corrente dos significados culturais que envolvem os bens de consumo presentes em sua vida (Featherstone, 1995; McCracken, 2003). Alinhado com essa visão, tem ganhado força um modelo de publicidade baseado no significado, que trata o consumidor como um indivíduo inserido num contexto e envolvido num projeto, ambos culturalmente constituídos. Diferentemente do consumidor racional, o indivíduo passa a ser visto numa busca constante não só de informações, mas, principalmente, dos significados que a publicidade oferece e que podem ser usados na construção de projetos culturais a respeito de si e do contexto cultural que o envolve (McCracken, 2005).

Amparada na edificação de um espírito coletivo (Baudrillard, 1990), a publicidade forja a identificação entre consumidor e marca através dos significados contidos em suas histórias consistentes, nos mitos reproduzidos para funcionar como bálsamo para as contradições na cultura de uma sociedade (Holt, 2005). De acordo com Rocha (2008), o mundo capitalista atual se apresenta como uma sala de visitas para esses mitos, ricamente presentes em anúncios publicitários, filmes, fotografia, moda, televisão e no próprio consumo através das marcas.

Portanto, estudar a construção de marcas atuais passa pela compreensão dos significados negociados pelas campanhas publicitárias e difundidos nas mais variadas esferas alcançadas pelo consumo. O mito reproduzido na publicidade, quando decifrado pela lente semiológica, tem muito a revelar através das histórias que conta a favor de uma marca. A seção seguinte tem como intuito aprofundar os conceitos que sustentam esse mito dentro do que prega a semiologia barthesiana.

\section{O Mito na Elaboração Teórica de Roland Barthes}

Um dos mais ricos e antigos paradigmas para o entendimento do significado e, por extensão, do mito, é a semiologia. Embora tenha seus primórdios localizados ainda na Grécia antiga, foi somente no início do século XX, que a semiologia passou a ser tratada em profundidade (Mick \& Oswald, 2006). Desde então, esta tem sido aplicada como um conjunto de instrumentos conceituais na abordagem sistemática dos mais variados sistemas de signos com o intuito de compreender como esses produzem sentido (Penn, 2002). Graças aos trabalhos desenvolvidos pelo semiólogo francês Roland Barthes na década de 1950, a relação entre semiologia e marketing ganhou força na Europa dos anos 1970 e, entre as décadas de 1980 e 1990, já havia se espalhado pelo resto do mundo, o reconhecimento das contribuições que a mesma poderia trazer para os estudos sobre consumo e comunicação (Scott, Stanford, \& Thompson, 2004; Silva \& Mello, 2010; Zhao \& Belk, 2008).

O pensamento de Barthes a respeito dos sistemas de significação avançou e atingiu um especial amadurecimento na fase estruturalista de seus estudos, período esse em que, baseado na proposta semiológica saussuriana, propôs-se a alcançar o sentido dos códigos implícitos nos sistemas simbólicos. O mito, um passo adiante em relação ao signo e ao objeto de nossa investigação, foi particularmente estudado nessa fase da semiologia barthesiana.

A semiologia proposta por Saussure (2006) procurou identificar uma estrutura universal e comum a todos os tipos de signos. Alinhado com a interpretação fenomenológica da realidade, o signo 
saussuriano consiste numa relação dialética entre um significante material e um significado abstrato, operando não de forma isolada, mas contextualizados com outros signos do sistema semiológico de discurso nos quais estão inseridos (Mick \& Oswald, 2006). Ou seja, o significante comportar-se-ia como um mediador cuja substância é sempre material, e o significado seria a representação psíquica desse algo, a apreensão do mesmo por parte de quem se expõe ao signo. Assim, objetos, sons, imagens, entre outros, serão considerados pela semiologia como os significantes em que repousam os significados dos signos verbal, gráfico, icônico, etc. (Barthes, 2006).

Já o mito, de acordo com Barthes, pode ser encontrado em tudo, visto que, sendo o universo infinitamente sugestivo, permite que cada objeto do mundo passe de uma existência fechada e muda a um estado aberto à apropriação da sociedade. Dessa forma, o discurso escrito, a fotografia, o cinema, a publicidade, tudo isso pode estar carregado pela fala mítica, exigindo cada um deles variados tipos de consciência e diferentes modos de leitura (Barthes, 2009). Apesar de poder ser entendido a partir do mesmo esquema tridimensional do signo, o mito se constitui num sistema particular, pois sua construção se dá a partir de uma cadeia semiológica existente antes dele, ou seja, o mito é um sistema semiológico segundo que deriva de um sistema semiológico primeiro. Não importa a multiplicidade das partes que o compõe, nem a natureza de sua matéria (verbal, visual, sonora), o signo captado no sistema primeiro será tomado pelo mito na sua totalidade, sendo submetido a um processo em que deixa de ser o termo final de uma primeira cadeia semiológica e passa a ser o primeiro termo do sistema segundo, esse ampliado em relação ao primeiro (Barthes, 2009).

Para entender o processo de ampliação que se dá de um sistema a outro, evitando ambiguidades entre os termos, Barthes propôs a adoção de uma nova nomenclatura para os componentes da estrutura ampliada (Figura 1). O significante do mito, sendo signo no primeiro sistema, ao se tornar significante, é nomeado de sentido no plano da língua e de forma no plano do mito. O significado, por sua vez, assume no segundo plano a denominação de conceito e, por fim, para que não se confunda o terceiro termo do plano do mito com o signo do sistema primeiro, Barthes propõe nomeá-lo de significação (Barthes, 2009).

\begin{tabular}{|c|c|c|}
\hline \multirow{4}{*}{ Língua } & Significante & Significado \\
\cline { 2 - 3 } & $\begin{array}{c}\text { Signo (sentido) } \\
\text { SIGNIFICANTE (FORMA) }\end{array}$ & $\begin{array}{c}\text { SIGNIFICADO } \\
\text { (CONCEITO) }\end{array}$ \\
\cline { 2 - 3 } & \multicolumn{2}{|c|}{ SIGNO (SIGNIFICAÇÃO) } \\
\hline
\end{tabular}

Figura 1. Estrutura do Mito.

Fonte: Adaptação dos autores a partir de Barthes, R. (2009). Mitologias (4a ed., p. 205). Rio de Janeiro: Difel.

O significante termina por assumir no mito um caráter duplo, pondo-se como termo final do sistema linguístico ou como termo inicial do sistema mítico. Em seu comportamento ambíguo, o significante do mito é simultaneamente sentido e forma. Enquanto sentido, o significante é pleno, já está completo na medida em que postula uma leitura, um saber, um passado. Ao se converter em forma, o sentido se esvazia, evapora sua história. Assim, o significante, anteriormente carregado por todo um sistema de valores, empobrece e, por isso mesmo, passa a requerer uma significação que o preencha, o que será alcançado a partir do conceito que passa a vesti-lo. É importante enfatizar que a forma não suprime o sentido. Depois de esvaziado, este é conservado, permanecendo à disposição da forma como uma espécie de reserva instantânea de história, pronta para ser acessada rapidamente e voltar a oferecer a riqueza submissa do sentido da qual pode se alimentar (Barthes, 2009).

No processo em que o sentido dá lugar à forma, vale a pena observar como atua o conceito que, sendo simultaneamente histórico e intencional, é, para Barthes, a força motriz que faz proferir o mito. Isso porque, ao estabelecer uma cadeia de causas e efeitos, de motivações e intenções, o conceito vestido de uma situação acaba por implantar toda uma nova história no mito que, apesar de construída 
em cima de um saber aberto, baseado em associações frágeis e ilimitadas, é portadora de uma unidade e de uma coerência que derivam de sua função: definir-se como tendência (Barthes, 2009).

A ampla disponibilidade de formas sugere não haver rigidez quando tratamos do conceito mítico que, por força da História, pode ser construído, modificado e até destruído completamente (Barthes, 2009). Exatamente por ser a História responsável pela transformação do real em discurso, cabe à mesma o comando sobre a vida e a morte do mito que, por isso, pode até ser antigo e duradouro, mas dificilmente será eterno. Por conta dessa dependência do contexto temporal em que está inserida, pode-se dizer, então, que a mitologia tem uma base histórica, já que a linguagem mítica não deriva da natureza das coisas, mas das circunstâncias que ditam o seu surgimento e sua manutenção (Barthes, 2009).

Uma última observação a ser feita é que, enquanto na língua, guardadas algumas limitações, o signo é geralmente arbitrário, na significação mítica sempre haverá uma carga de motivação necessária à própria duplicidade do mito que, através de suas analogias, tem como princípio transformar a história em natureza. Esse processo que converte eventualidade em eternidade, segundo Barthes (2009), é o que está na essência da ideologia que encontra no mito um valioso instrumento de indução numa sociedade ricamente povoada de significações.

\section{Procedimentos Metodológicos}

A presente pesquisa se caracteriza como um estudo qualitativo interpretativista (Creswell, 2007) por meio do qual construímos categorias empíricas que dessem conta da variedade de mitos identificados. Inspirados em Barthes, na categorização dos mitos e demais dimensões simbólicas, adotamos um caráter indutivo ${ }^{(3)}$. Lembramos que, por conta do caráter interpretativo próprio da pesquisa qualitativa, a subjetividade do pesquisador está presente em todo o desenvolvimento da investigação. Por outro lado, ao assumir certo grau de indução, a investigação qualitativa pode chegar à sua forma mais pura, despojada de teoria e hipóteses, mas permanecendo aberta à descoberta, mesmo quando se utiliza de um quadro teórico prévio, uma vez que este não será operado no nível de variáveis (Leão, Mello, \& Vieira, 2009).

O corpus de pesquisa (Bauer \& Aarts, 2008) foi construído a partir de 80 peças publicitárias impressas fornecidas pela agência de comunicação da marca em outubro de 2011 e que dão conta de todas as campanhas desenvolvidas entre 1998 e 2010. Como já mencionado, os significados associados a uma marca assumem um fluxo e são passíveis de identificação tanto na proposta de identidade pensada pela empresa, quanto na imagem construída pelo consumidor final. Sem ignorar a importância desses dois extremos no processo, nesse momento da pesquisa, optamos por estudar especificamente a riqueza simbólica da publicidade, em que o significado ganha expressão de forma mais evidente. O corpus comportou a matriz visual, baseada nas imagens (fotografias, ilustrações, $\operatorname{símbolos}^{(4)}$, entre outros) presentes nos anúncios e outdoors da marca, e a matriz verbal que contemplou as mensagens textuais (chamadas, textos explicativos e slogans) veiculadas nessas mesmas peças de comunicação.

A análise de dados se baseou na abordagem semiológica barthesiana (Barthes, 2006) e se deu a partir de uma sequência de etapas aplicadas a cada uma das peças publicitárias estudadas. Amparado no modelo proposto por Barthes, a análise considerou o primeiro e o segundo sistema semiológicos, cada um deles com seus respectivos componentes analisados segundo o fluxo de sentido. No primeiro passo, foram elencados todos os elementos, verbais e visuais, assumidos como significantes, a partir dos quais, aferidos seus possíveis significados, pudemos chegar aos respectivos signos, produto final do sistema primeiro. Em seguida, tomamos esses signos como significantes do segundo sistema que, quando agrupados de acordo com os conceitos que carregavam, puderam apontar os possíveis mitos reproduzidos dentro do contexto em que a publicidade da marca foi desenvolvida. Com o intuito de validar os resultados da pesquisa, realizamos uma triangulação por meio de uma análise adicional feita 
pelo segundo autor deste trabalho ${ }^{(5)}$ (Merriam, 1998). A adoção dessa técnica contribui tanto para a validade quanto para a confiabilidade da investigação, compondo um quadro mais evidente do fenômeno por meio da convergência dos resultados (Paiva, Leão, \& Mello, 2011).

Para exemplificar esse processo de análise, consideremos um dos anúncios da marca, em que uma stripper retira de sua perna nua uma fita vermelha amarrada em forma de laço (Figura 2A). Esse adorno, tratado por nós como significante, é universalmente usado para enfeitar as embalagens que envolvem aquilo que se quer presentear, portanto, foi natural inferir que sua presença na peça significava a existência de um presente. Como a personagem retira o laço do próprio corpo, a conclusão é de que ela mesma se oferece como prenda sexual para o homem. Sendo assim, o que caracterizamos como um tipo de mulher-presente veio a compor, somado a outros signos com a mesma conotação (stripper, ninfeta, etc.), o grupo dos elementos constituintes do signo que denominamos papéis sexuais. Este, por sua vez, passou a integrar o conceito apelos eróticos do sistema segundo, formado ainda por outros dois grupos de signos (comportamentos e práticas sexuais). Finalmente, o poder sugestivo da erotização aparece nutrindo o mito do elogio ao sexo. Esse raciocínio analítico foi aplicado em todas as campanhas para a análise de cada um dos significantes que, agrupados de acordo com os significados e signos para os quais apontavam, foram convergindo para unidades de sentido cada vez mais amplas até se chegar aos mitos.

Com o intuito de ultrapassar a pura identificação dos mitos, adotamos as noções de diacronia e sincronia (Saussure, 2006), que podem contribuir, respectivamente, com a análise da evolução dos mitos ao longo do tempo, bem como com a compreensão das relações que esses estabelecem entre si. O estudo diacrônico se baseia no caráter sucessivo de uma língua ao longo do tempo, marcado por mudanças que resultaram da relação entre determinado fato e aqueles que o precederam ou sucederam. Já o estudo sincrônico se atém às simultaneidades estudadas a partir da estrutura e das relações entre os fatos que existem, ao mesmo tempo, em determinado momento de um sistema linguístico. A mitologia barthesiana não traz em sua abordagem os conceitos de diacronia e sincronia. Apesar disto, considerando que a semiologia saussuriana se dedica ao estudo do signo - verbal e não verbal - e que é a partir desse signo que Barthes se expande para a proposta do mito, enxergamos aqui a oportunidade para uma compreensão ampliada do fenômeno mitológico.

\section{Descrição dos Resultados}

A seguir, apresentamos os mitos a que chegamos, cada um deles discutido e ilustrado, seguidos, na sequência, pela análise diacrônica e sincrônica que os envolve. Por conta da limitação de espaço, é dado apenas um exemplo que seja ilustrativo de cada uma das manifestações mitológicas, podendo uma mesma peça aparecer ilustrando facetas de diferentes mitos. Reconhecemos, todavia, que seja apenas na totalidade das imagens que a complexidade dessas narrativas possa ser amplamente evidenciada.

\section{Os mitos por trás da marca Chilli Beans}

A análise das 80 peças publicitárias da marca Chilli Beans resultou na identificação de 12 mitos. Seguindo a aparição dos mitos na ordem cronológica das campanhas, a Tabela 1 apresenta o universo, sinteticamente representado, das unidades de significação encontradas. Como se observa, os seis níveis percorridos na análise inicial passam, nesse momento, a ser representados por apenas três níveis fundamentais e suficientes para os nossos objetivos. 
Tabela 1

\section{Síntese de Signos, Conceitos e Mitos Reproduzidos pela Chilli Beans}

\begin{tabular}{lll}
\hline SIGNOS & CONCEITOS & MITOS \\
\hline $\begin{array}{l}\text { Disputa entre mulheres } \\
\begin{array}{l}\text { Sinais de luta; presença de } \\
\text { antagonistas; agressor versus vítima; } \\
\text { morena versus loira. }\end{array}\end{array}$ & $\begin{array}{l}\text { Competírito de competição atribuído às } \\
\text { mulheres em diversas esferas } \\
\text { (afetiva, estética, profissional). }\end{array}$ & $\begin{array}{l}\text { Rivalidade Feminina } \\
\text { Senso comum de que as mulheres } \\
\text { são eternas rivais. }\end{array}$ \\
\hline $\begin{array}{l}\text { Padrão de beleza } \\
\begin{array}{l}\text { Corpos magros; pele jovem, perfeita } \\
\text { e bronzeada; cabelos lisos, loiros ou } \\
\text { castanhos. }\end{array}\end{array}$ & $\begin{array}{l}\text { Ideal estético } \\
\text { Perfil de beleza imposto como }\end{array}$ & $\begin{array}{l}\text { Ditadura da Beleza } \\
\text { cobrigatoriedade de adoção do } \\
\text { padrão vigente como aceitação e sucesso de } \\
\text { inclusão social. }\end{array}$ \\
\hline
\end{tabular}

\section{Natureza e clima tropicais}

Vegetação exuberante e animais próprios do Brasil; Personagens bronzeados; exposição dos corpos (calor).

\section{Sensualidade aflorada}

Posturas sensuais e libertinas adotadas pelo brasileiro em suas relações afetivas.

Misticismo plural
Adoção de símbolos místicos
oriundos de crenças diversas (flor de
lótus, elefante cor-de-rosa,
triângulo, etc.).

\section{Tropicalidade}

Brasil associado com verão, natureza exuberante e povo de sangue quente (latino).

\section{Malemolência sexual}

Comportamentos sexuais fortemente marcados pela sensualidade aflorada e malícia do brasileiro.

\section{Sincretismo religioso}

Hábito brasileiro de um mesmo indivíduo conciliar a tradição católica, sobretudo, com outras crenças (horóscopo, candomblé, espiritismo).

Posse material
Disputa material, consumo em
excesso, ostentação de objetos de
luxo, ambientes opulentos e estética
requintada.

\section{Comportamentos sexuais}

Relação homoafetiva; personagens insinuantes e sensuais.

\section{Papéis sexuais \\ Cafajeste; conquistador; prostituta; ninfeta; virgem, stripper.}

\section{Práticas sexuais}

Exibicionismo (nudez pública); strip-tease; masturbação; fetiches sexuais (sexo a três, jogos de dominação, etc.).

Independência feminina \\ Independência feminina}

Posse de bens e assunção de postos, inclusive sexuais, tradicionalmente associados ao universo masculino.

\section{Distinção por posse}

Posses materiais como marcadores de distinção social.

\section{Brasilidade}

Conjunto de características atribuídas ao Brasil (caloroso, sensual, exuberante, múltiplo).

\section{Poder Material}

Poder socialmente concedido às classes abastadas.

\section{Apelos eróticos}

Conjunto de comportamentos, papéis e práticas que apelam para o erotismo.

\section{Elogio ao sexo}

Atmosfera erotizada que sugere ou incita de modo elogioso a prática sexual.

\section{Apropriação do falo \\ Mulher Alfa}

Mulher independente exerce o poder Mulher atual como protagonista na do falo tradicionalmente conferido aos homens. realização de seus desejos profissionais e pessoais. 
Tabela 1 (continuação)

\begin{tabular}{|c|c|c|}
\hline SIGNOS & CONCEITOS & MITOS \\
\hline Sujeição feminina & Submissão ao falo & Mulher Beta \\
\hline $\begin{array}{l}\text { Mulher na condição social de } \\
\text { companheira que serve } \\
\text { passivamente ao homem, seja como } \\
\text { objeto de dominação sexual, seja no } \\
\text { desempenho de papéis (mãe e dona } \\
\text { de casa) convencionalmente } \\
\text { instituídos como femininos dentro } \\
\text { da sociedade tradicional. }\end{array}$ & $\begin{array}{l}\text { Mulher submissa diante do poder do } \\
\text { falo conferido tradicionalmente ao } \\
\text { homem. }\end{array}$ & $\begin{array}{l}\text { Mulher como instrumento de prazer, } \\
\text { objeto de dominação e } \\
\text { autoafirmação do homem; dedicada } \\
\text { à missão de perpetuação e zelo da } \\
\text { família. }\end{array}$ \\
\hline Relações sexistas & Distinção por gênero & Poder Sexista \\
\hline $\begin{array}{l}\text { Condições favoráveis a um } \\
\text { personagem alfa diante de um } \\
\text { personagem beta. Geralmente, é o } \\
\text { homem (dominador/conquistador) } \\
\text { que aparece na condição de líder em } \\
\text { relação à mulher. }\end{array}$ & $\begin{array}{l}\text { Em geral, a distinção socialmente } \\
\text { instituída privilegia o gênero } \\
\text { masculino. }\end{array}$ & $\begin{array}{l}\text { Poder socialmente concedido, } \\
\text { principalmente, ao gênero } \\
\text { masculino, mas também se aplica à } \\
\text { mulher alfa. }\end{array}$ \\
\hline Protagonismo masculino & Exercício do falo & Homem Alfa \\
\hline $\begin{array}{l}\text { Homem no desempenho de } \\
\text { atividades que confirmam sua } \\
\text { condição de dominador, } \\
\text { conquistador, provedor e protetor. }\end{array}$ & $\begin{array}{l}\text { Homem exercita o poder do falo, } \\
\text { que lhe é concedido socialmente. }\end{array}$ & $\begin{array}{l}\text { Figura masculina com postura de } \\
\text { líder, protagonista, provedor e } \\
\text { protetor. }\end{array}$ \\
\hline Cenários citadinos & Universo urbano & Urbanidade \\
\hline Ambientes urbanos; noite; carros. & $\begin{array}{l}\text { Contextos pontuados por } \\
\text { velocidade, mudança e intensidade } \\
\text { dos estilos de vida. }\end{array}$ & $\begin{array}{l}\text { Cultura marcada pelo frenesi } \\
\text { inerente às grandes cidades. }\end{array}$ \\
\hline
\end{tabular}

\section{Celebração da pluralidade}

Chamadas que exaltam a diversidade (Para todas as espécies); destaque para a multiplicidade simbólica dos indivíduos.

\section{Especificidades do indivíduo}

Personagens ou substitutos simbólicos que remetem a características (personalidade, vestuário, práticas, etc.) que compõem estilos de vida e personalidades próprias.

\section{Ecletismo}

Multiplicidade de tipos individuais da sociedade; versatilidade de um mesmo indivíduo que incorpora vários estilos de vida ao mesmo tempo.

\section{Individualidade}

Conjunto de características próprias de identidades particulares ou ligadas a elementos específicos de determinado grupo.

\section{Sujeito Pós-Moderno}

Indivíduo atual que transita por várias e distintas esferas, assume comportamentos múltiplos, mas valoriza as particularidades que constroem sua identidade.

\section{Atmosfera festiva}

Situações lúdicas; referências a infância, festa, música, bebida, cigarro.

Cultura do excesso
Chamadas (Sua vida pede muitos) e
imagens que pregam a busca do
prazer por meio de intensidade nos
estilos de vida e no consumo.

Espírito Carpe Diem
Estilo de vida guiado pela busca
intensa e imediata do prazer,
dispensando uma preocupação com
o futuro.

\section{Elogio ao Prazer}

Estímulo, sobretudo aos jovens, para a adoção de uma vida intensa, movida pelas diversas formas de prazer que se apresentam, inclusive no consumo.

\section{Juventude}

Vestuário, práticas, posturas e personagens juvenis. 
Entre os resultados, chama atenção a forte presença da figura feminina que aparece na quase totalidade das campanhas e, na maioria delas, ocupando o papel principal nos temas abordados. Já em sua primeira campanha, a Chilli Beans aborda essa questão quando põe duas mulheres se digladiando pelos óculos de uma delas (Figura 2B), o que traz à cena um reforço à rivalidade feminina. No caso específico, trata-se da disputa entre loiras e morenas. A loira, ao mesmo tempo em que é um sucesso nacional, haja vista a quantidade de mulheres que adotam as cores claras para tingir seus cabelos e o seu reconhecido apelo sexual entre os homens, também se vê constantemente hostilizada nos jargões populares que põem em dúvida a sua inteligência, provavelmente por representar uma forte concorrente da mulher morena genuinamente brasileira.
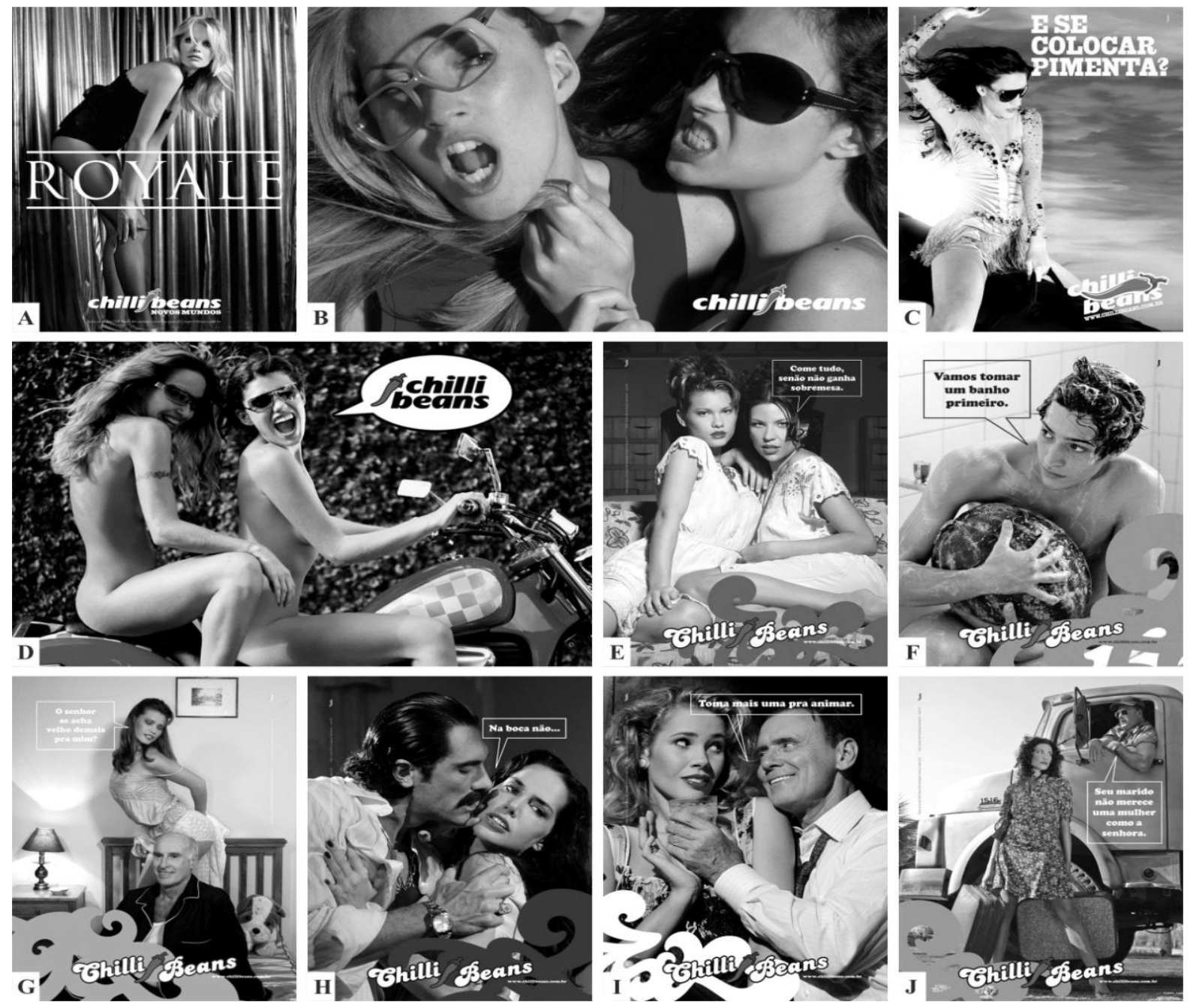

Figura 2. Anúncios da Marca Chilli Beans (parte 1).

Fonte: Fracta Propaganda e Marketing. (2009a). Campanha Novos Mundos - Royale (Figura A). São Paulo: Autor; Fracta Propaganda e Marketing. (1998). Campanha Ciúmes (Figura B). São Paulo: Autor; Fracta Propaganda e Marketing. (2010). Campanha Pimenta (Figura C). São Paulo: Autor; Fracta Propaganda e Marketing. (2000). Campanha Peladas (Figura D). São Paulo: Autor; e Fracta Propaganda e Marketing. (2005). Campanha Pornochanchada (Figura E, F, G, H, I e J). São Paulo: Autor.

Independentemente de ser loira ou morena, padrões que se alternam na maioria das peças estudadas, a mulher da Chilli Beans está submetida à chamada ditadura da beleza, segundo mito a recair, principalmente, sobre as personagens femininas materializadas em corpos magros, jovens e, muitas vezes, bronzeados. De maneira distinta, o retrato dos corpos masculinos, que variam de jovens e atléticos até maduros e marcados pela calvície e pelo sobrepeso, revela que é dada ao homem uma liberdade frente à ditadura estética reinante, diferentemente do que acontece com as mulheres, que são induzidas a enxergar na beleza o único caminho capaz de levá-las ao sucesso e à felicidade. 
Além da beleza e da sensualidade das personagens femininas, a atmosfera de conquista vendida pela Chilli Beans é fartamente alimentada pelo teor erótico que permeia suas peças publicitárias. Essa erotização, que se expressa em práticas, papéis e comportamentos sexuais, leva ao mito traduzido pelo elogio ao sexo expresso de modos bem distintos, que vão da exposição sensual de belos corpos (Figura 2D) até chamadas provocantes, como: E se colocar pimenta? (Figura 2C). Entre as práticas sexuais retratadas, além do conhecido jogo de sedução entre homem e mulher, destacam-se performances de strip-tease (Figura 2A), convites para o sexo a três (Figura 2E) e para a masturbação (Figura 2F). Os papéis sexuais femininos compreendem da ninfeta (Figura 2G) à prostituta (Figura 2H). Já a figura masculina ganha corpo no cafajeste saliente e tarimbado (Figura 2I), no senhor inseguro diante da jovem ninfeta (Figura $2 \mathrm{G}$ ) e no pós-adolescente que acabou de descobrir o sexo (Figura 2F). Os comportamentos, por fim, oscilam entre a incitação à traição (Figura 2J) e o falso moralismo, que disfarça desejos reprimidos (Figura 3A).

Em razão do forte apelo erótico das narrativas veiculadas, os papéis assumidos pelas personagens femininas são em grande medida desempenhados dentro desse contexto. $\mathrm{O}$ maior destaque está no mito da mulher beta, envolta de sensualidade, assumida como um instrumento de prazer, submetida à dominação masculina e incumbida de inspirar seus fetiches sexuais. A sensualidade pode ser observada no uso de peças de vestuário provocantes e na exposição sensual do corpo (Figuras 2D e 3B). Cenas de strip-tease (Figura 2A), convites para a prática de sexo com mais de uma parceira (Figura 2E) e jogos de dominação (Figura 3B) ilustram gestos de doação da mulher que se presta como um verdadeiro objeto sexual para o homem. Vale destacar que, de modo distinto, duas peças retratam a passividade da mulher beta por meio do papel da avó devotada ao cuidado com o lar (Figura 3C) e, simbolicamente, na figura da mãe representada pelo gesto de aconchego e amamentação próprio da maternidade (Figura 3E). Nesses dois casos há, portanto, um desvio em que o papel profano da mulher erotizada, ativa ou passiva, dá lugar ao papel sagrado da mulher provedora da família tradicional e conservadora.
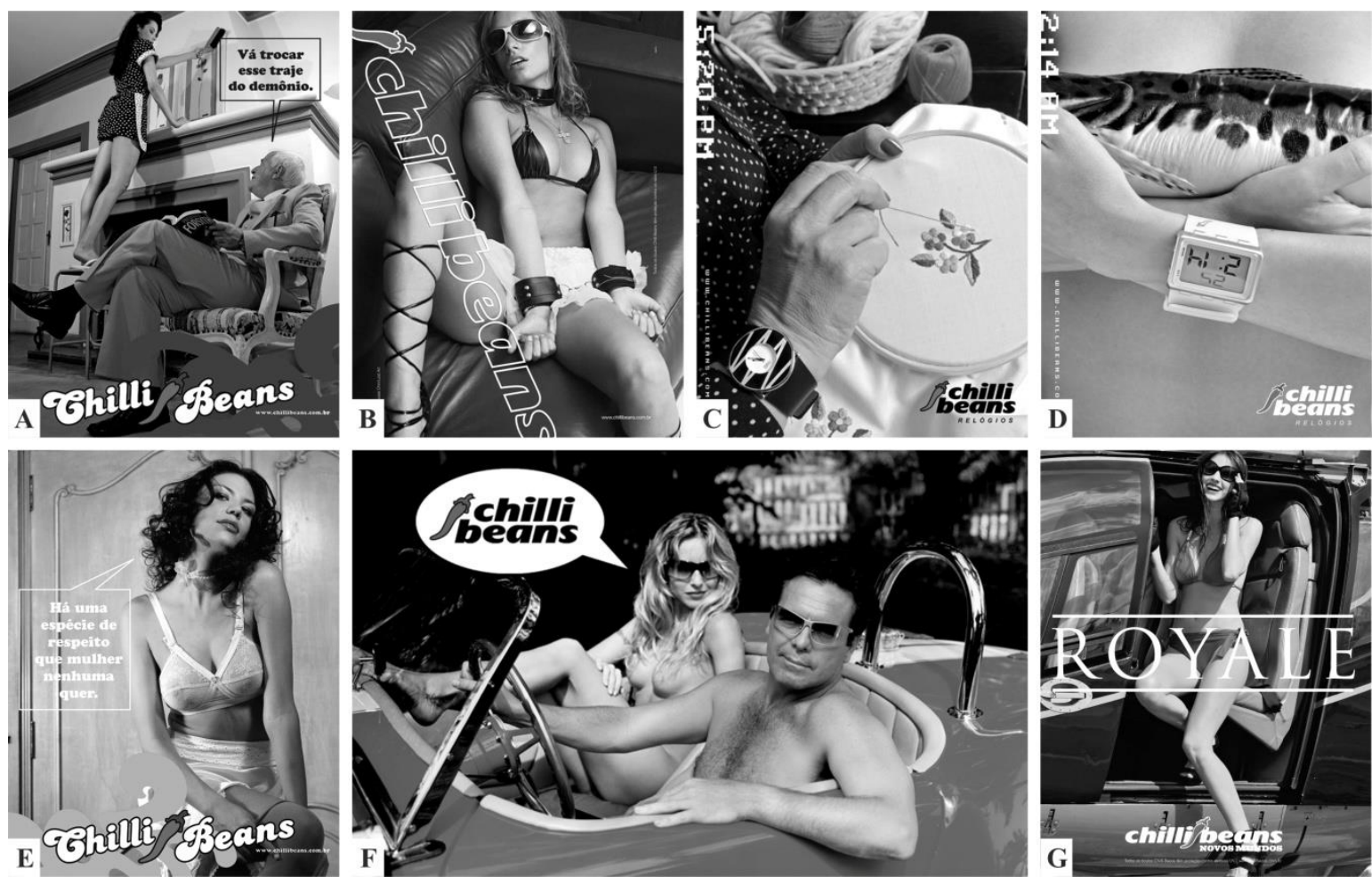

Figura 3. Anúncios da Marca Chilli Beans (parte 2).

Fonte: Fracta Propaganda e Marketing. (2005). Campanha Pornochanchada (Figura A e E). São Paulo: Autor; Fracta Propaganda e Marketing. (2002). Campanha Fetiche (Figura B). São Paulo: Autor; Fracta Propaganda e Marketing. (2006). Campanha Relógios (Figura C e D). São Paulo: Autor; Fracta Propaganda e Marketing. (2000). Campanha Peladas (Figura F). São Paulo: Autor; e Fracta Propaganda e Marketing. (2009a). Campanha Novos Mundos - Royale (Figura G). São Paulo: Autor. 
De modo oposto à mulher beta, algumas personagens se vestem com o mito da mulher alfa que assume uma posição de protagonismo em contextos antes frequentados somente por homens. No campo sexual, essa faceta se manifesta tanto no retrato de casais homoafetivos femininos, situação em que a figura masculina é totalmente dispensável (Figura 2D), quanto no de mulheres que abandonam uma condição de passividade e tomam iniciativa em direção à realização de seus próprios desejos (Figura 3E). De outra forma, a emancipação feminina se manifesta simbolicamente quando algumas personagens assumem o controle de situações que vão da pilotagem de uma motocicleta pesada (Figura 2D) à montaria de um touro mecânico (Figura 2C), elementos esses fortemente associados ao universo masculino.

A aparição masculina nas campanhas estudadas é bem mais discreta, no entanto, chama atenção que, na quase totalidade delas, a figura masculina assume posturas que apontam para o homem alfa que, diante da mulher, toma para si os papéis ativos de conquistador, provedor e dominador. No geral, os homens da Chilli Beans se vestem de virilidade, inclusive, quando encarnam o conquistador barato cujo amor bandido - fetiche feminino - só o cafajeste tem a oferecer (Figura 2I). O macho alfa se apresenta também na pele do homem provedor, geralmente, mais maduro e capaz de suprir sua parceira com a segurança que ela procura, seja sentimental ou financeira (Figura 3F). Por fim, de maneira menos marcante, o homem é retratado ainda nas figuras de músico, disc jockey e playboy que, apesar de não assumirem posturas relacionadas a sexo ou a relacionamentos afetivos, são apresentados em contextos de êxito ou liderança.

Tecendo toda sorte de interação entre os personagens está o mito do poder sexista, para o qual são de fundamental importância as construções de sentido feitas em torno do conceito de falo. No caso do homem alfa, há o que se pode chamar de exercício do falo, tanto na sua ostentação, como na sua reafirmação. A ostentação do falo se dá quando a figura masculina assume a condição de conquistador e provedor (Figura 2I), enquanto a reafirmação pode ser observada nas várias situações em que o homem, sendo mais velho, investe na conquista de uma mulher mais jovem, um verdadeiro troféu que ratifica sua virilidade (Figura 3F). O poder do falo também está nos mitos que envolvem personagens femininas. No caso da mulher beta, identificamos uma submissão ao falo (Figuras 2A e 3B). De maneira oposta, na emancipação feminina, podemos dizer que há uma apropriação do falo empreendida pela mulher alfa, que assume posturas convencionalmente masculinas (Figuras 2C e 2D).

Outra faceta do poder se revela no mito do poder material, que aparece nas situações em que a ostentação de bens por alguns personagens remontam à distinção social advinda do alto poder aquisitivo materializado em artigos de luxo, tais como helicóptero (Figura 3G) e carro conversível (Figura 3F), fazem referência à busca do prazer que se pode alcançar por meio do consumo material excessivo (Figura 4A), ou denotam, finalmente, as vantagens adquiridas pela posse de um determinado bem, como acontece no caso de mulheres que se põem em disputa pelos mesmos óculos de sol (Figura 2B). 

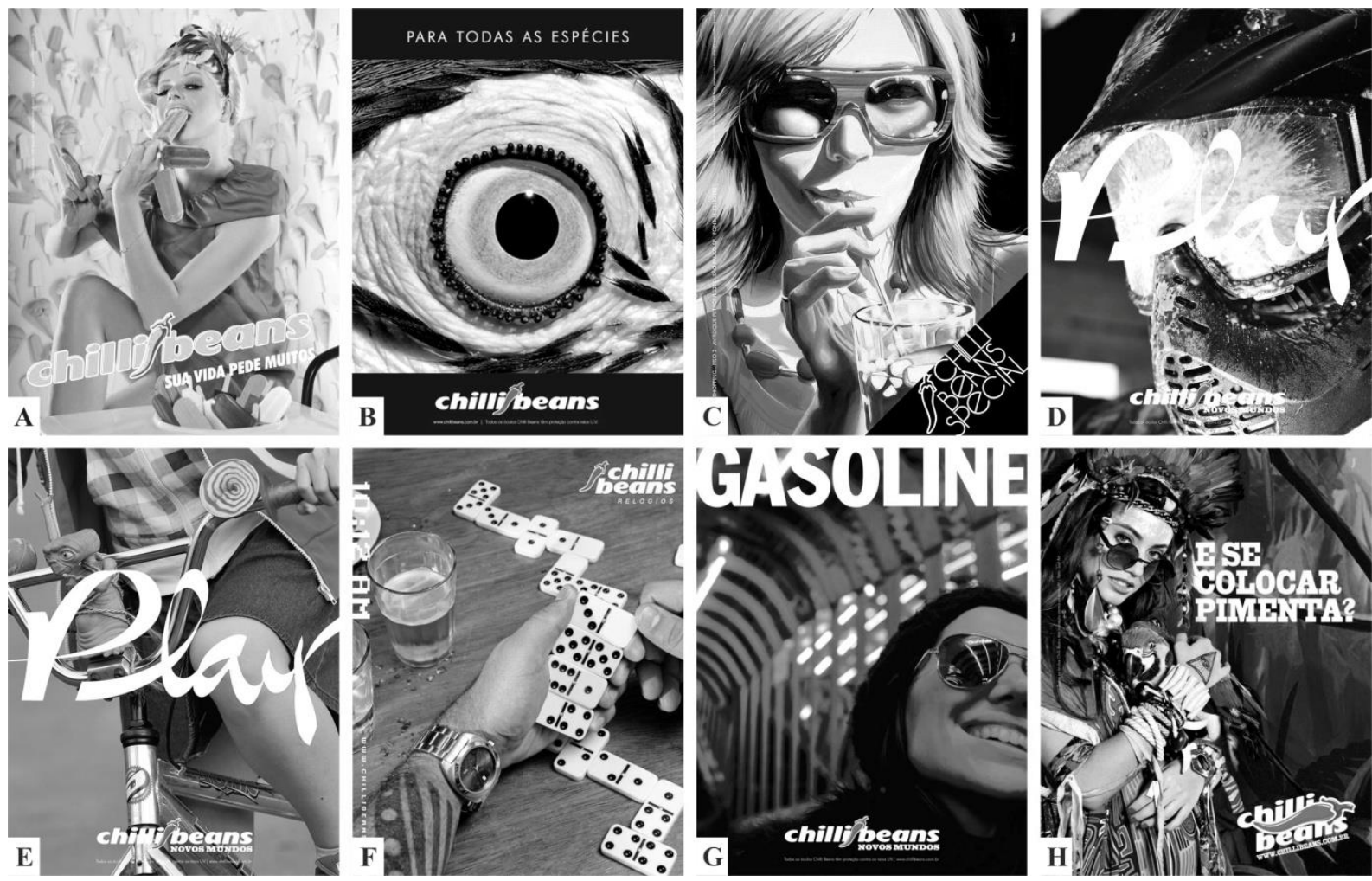

Figura 4. Anúncios da Marca Chilli Beans (parte 3).

Fonte: Fracta Propaganda e Marketing. (2008). Campanha Compulsão (Figura A). São Paulo: Autor; Fracta Propaganda e Marketing. (2003). Campanha Olhos (Figura B). São Paulo: Autor; Fracta Propaganda e Marketing. (2007). Campanha Special (Figura C). São Paulo: Autor; Fracta Propaganda e Marketing. (2009b). Campanha Novos Mundos - Play (Figura D e E). São Paulo: Autor; Fracta Propaganda e Marketing. (2006). Campanha Relógios (Figura F). São Paulo: Autor; Fracta Propaganda e Marketing. (2009c). Campanha Novos Mundos - Gasoline (Figura G). São Paulo: Autor; e Fracta Propaganda e Marketing. (2010). Campanha Pimenta (Figura H). São Paulo: Autor.

O mito do sujeito pós-moderno, caracterizado principalmente pela valorização do ecletismo e da individualidade que envolve o indivíduo contemporâneo, aparece em algumas campanhas em que esses elementos são trabalhados em cima do conjunto de peças que trazem uma variedade de personagens, literal ou simbolicamente representados, cada qual marcado por características próprias (Figuras 4B, 4D, 4E, 4F, e 4G).

Outro mito com forte presença nas campanhas da Chilli Beans é o elogio ao prazer, que repousa sobre o espírito carpe diem baseado num universo festivo, numa cultura de excessos e no signo da juventude, os três intimamente associados. Dessa forma, a busca pelo prazer, fortemente vinculada à figura do jovem, encontra esteio na atmosfera festiva embalada por música, bebidas e cigarros (Figura 4C e 4F), assim como no consumo exacerbado que contribui para um estilo de vida marcado pela intensidade (Figura 4A). O elogio ao prazer está ainda no tom lúdico pintado em ambientes de esportes (Figura 4D), brincadeiras (Figura 4E) e jogos (Figura 4F), retratados em algumas peças publicitárias.

Algumas situações retratadas se desenvolvem dentro de contextos edificados com base no mito da urbanidade, alimentado pelo frenesi e pelo dinamismo próprios dos grandes centros urbanos. Esse mito encontra-se representado no caráter instável e vibrante de luzes desfocadas que pontuam cenas noturnas e nos elementos típicos da paisagem urbana, como veículos e ambientes de entretenimento (Figura 4G).

Um último mito identificado nas análises foi o da brasilidade, que vende o Brasil como um país tropical através de sua natureza exuberante (Figuras 4B e 4H) e da celebração do verão que tanto contribui para a composição de belos corpos bronzeados (Figura 2C). Ajudado por essa beleza tropical, a brasilidade também se expressa por meio da sensualidade aflorada e, por conseguinte, da 
malemolência sexual atribuída ao povo brasileiro (Figuras $2 \mathrm{G}$ e 2I). Por fim, esse mito aparece ainda no sincretismo religioso que marca a cultura nacional, representado em uma das campanhas pela presença de símbolos místicos vinculados a crenças diversas (Figura 4H).

\section{Análise diacrônica: a evolução dos mitos reproduzidos pela Chilli Beans}

Num panorama geral, o acompanhamento de como os mitos identificados se apresentam cronologicamente ao longo das campanhas (Tabela 2) revela que apenas dois deles aparecem pontualmente - rivalidade feminina e urbanidade - enquanto os demais têm uma presença consistente no histórico de peças publicitárias desenvolvidas pela marca. Individualmente, vale destacar os mitos elogio ao sexo e ditadura da beleza pela presença marcante que têm em quase todas as campanhas estudadas.

Tabela 2

\section{Cronologia da Reprodução de Mitos nas Campanhas da Chilli Beans}

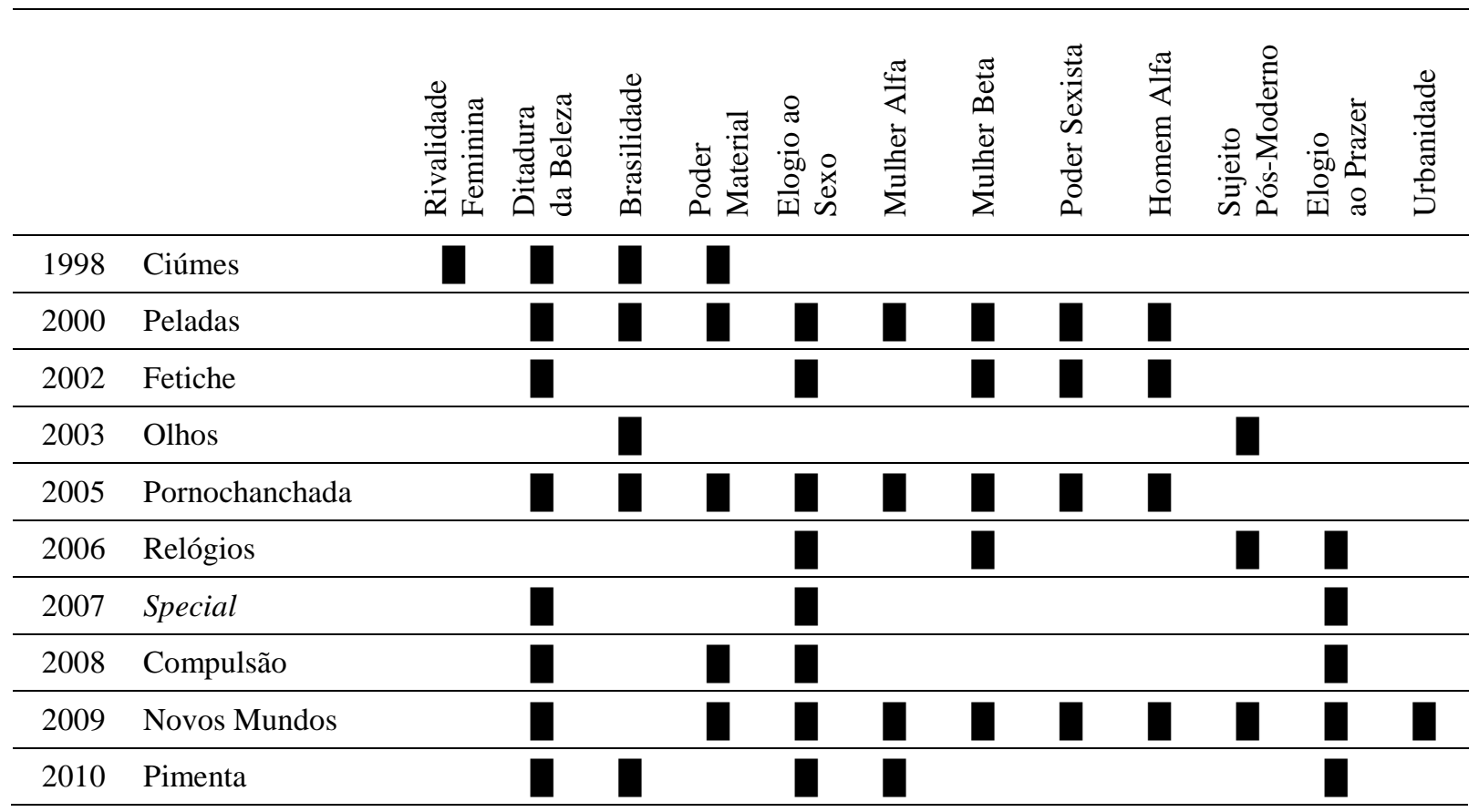

Primeira campanha desenvolvida pela Chilli Beans, Ciúmes (Figura 2B), insere o produto anunciado dentro do contexto inusitado de uma briga entre duas mulheres. Uma peculiaridade dessa campanha em relação às demais está na presença do mito da rivalidade feminina, amparo principal para o mote da campanha, que foi reproduzido essa única vez. Os óculos de sol, objeto de disputa na cena, revelam o mito do poder material quando aparecem como um bem capaz de promover vantagens e distinção ao seu possuidor. Na campanha, estão ainda os mitos da ditadura da beleza, incorporado nas duas belas personagens, e da brasilidade, presente nos corpos bronzeados e no ambiente ensolarado da cena retratada.

Em sua segunda campanha, a marca apostou numa atmosfera provocante de forte sensualidade, tema esse que viria a ser um de seus favoritos a partir de então. Na transição entre as campanhas Ciúmes e Peladas (Figuras 2D e 3F), o que primeiro chama atenção é o aumento dos mitos reproduzidos e a mudança das questões tratadas. $\mathrm{O}$ antagonismo inerente à rivalidade feminina da primeira campanha dá lugar à sugestão de um relacionamento homoafetivo entre duas mulheres que ajuda a compor o mito do elogio ao sexo da segunda campanha. Esse mito, por sua vez, ganha reforço quando as personagens femininas se vestem tanto com a passividade da mulher beta, quanto com a liderança da mulher alfa. Já as personagens masculinas, assumindo a condição de homem alfa, 
completam o cenário permeado pelo poder sexista e pelo poder material exercido nas relações entre as personagens. Nessa campanha, as mulheres continuam alinhadas com a ditadura da beleza em sua contribuição para o cenário envolto de brasilidade.

Dois anos depois, a campanha Fetiche (Figura 3B) reproduz muitos dos mitos da campanha anterior, com algumas diferenças no modo como esses são tratados. O elogio ao sexo se volta para o universo dos fetiches sexuais, o que ressalta ainda mais a mulher beta dominada por um homem alfa, nesse caso apenas sugerido. O poder sexista exercido por este está claramente materializado nas cordas e nas algemas que imobilizam os corpos bronzeados de belas mulheres que, por conta de tais características físicas, incorporam o mito da ditadura da beleza.

Olhos representou uma verdadeira ruptura - estética e conceitual - na publicidade desenvolvida até então pela Chilli Beans (Figuras 4B). A primeira grande mudança foi a opção por retratar animais no lugar de pessoas em peças minimalistas diagramadas em torno de olhos grandes e expressivos. A outra diferença de abordagem ficou por conta do abono do tom erotizado das campanhas anteriores, substituído agora pela representação dos variados estilos de vida e peculiaridades dos consumidores simbolicamente representados por cada uma daquelas espécies retratadas. Estava em evidência, então, o sujeito pós-moderno, que valoriza sua individualidade sem abrir mão de ser plural. Nessa campanha, a brasilidade se manifestou através das espécies animais, em sua maioria, naturais da fauna brasileira.

As relações afetivas carregadas de erotismo voltam à cena na campanha Pornochanchada (Figuras 2E, 2F, 2G, 2H, 2I, 2J, 3A e 3E). Baseada na estética e nas temáticas tratadas por essa vertente do cinema brasileiro da década de 70, a campanha retoma o estilo provocador que marca a publicidade da Chilli Beans desde o seu início. O elogio ao sexo está em cada uma das cenas retratadas, boa parte delas pintadas com cores mais fortes do amor bandido. A mulher beta e a mulher alfa são incorporadas em novas personagens que têm participação destacada no jogo da sedução. Nessa atmosfera, o homem alfa se apresenta, principalmente, na pele do cafajeste, que faz valer o poder (sexista) do falo de que tanto se vangloria para conquistar essa nova mulher, tão bela quanto as anteriores, em conformidade, portanto, com a ditadura da beleza. $\mathrm{O}$ relacionamento entre homem e mulher é marcado ainda pelo mito do poder material, manifestado numa cena que retrata a interação entre um senhor (rico) e sua jovem empregada doméstica (pobre). A brasilidade dessa campanha fica por conta da sensualidade aflorada dos personagens retratados por esse estilo cinematográfico genuinamente brasileiro.

Na campanha Relógios (Figuras 3C, 3D e 4F), há um retorno ao mito do sujeito pós-moderno inaugurado na campanha Olhos e marcado pela individualidade e pelo ecletismo, denotado na variedade de personagens retratados. Em duas de suas peças, a campanha apresenta o mito da mulher beta de uma forma distinta, representada em posições femininas convencionais voltadas para o papel de mãe e o cuidado com o lar. Outra novidade é o mito do elogio ao prazer, que, a partir de então, passou a figurar de maneira marcante nas campanhas veiculadas pela Chilli Beans. O mito do elogio ao sexo, por sua vez, aparece discretamente em apenas uma das peças.

Realizada em duas etapas, a campanha Special (Figura 4C) reproduziu pinturas de um artista inglês que retratou, num primeiro momento, personagens criados a partir de modelos e, numa segunda fase, consumidores reais da marca, todos eles fazendo uso de óculos de sol. O clima festivo que vestiu as personagens retratadas na campanha revela a importância que o mito do elogio ao prazer passaria a ter dentro da publicidade da Chilli Beans. Nos retratos de belas mulheres pintadas em cores fortes e emolduradas pela ditadura da beleza também está presente, ainda que apenas insinuado nos gestos das personagens, o mito do elogio ao sexo.

Em Compulsão (Figura 4A), são apresentados os mesmos mitos da campanha anterior somados ao poder material - na ocasião, tratado de forma diferente daquela adotada nas demais campanhas que estaria nas mãos daqueles a quem é permitido o consumo em excesso de bens diversos, condição esta pregada por chamadas que estimulam a adoção de um estilo de vida marcado pelo deleite materialista, um elogio ao prazer, portanto. $\mathrm{O}$ mito do elogio ao sexo vem insinuado nos gestos da 
personagem feminina que, como esperado, também está enquadrada no que prega a ditadura da beleza.

Assim como em Olhos e Relógios, a campanha Novos Mundos (Figuras 2A, 4D, 4E, e 4G) dá destaque ao mito do sujeito pós-moderno. Subdividida em quatro estilos (Gasoline, Play, Royale e Vírus), a campanha retrata de maneira rica a multiplicidade de indivíduos em suas respectivas peculiaridades. A tendência de reprodução do elogio ao prazer é mantida por meio de cenas lúdicas e festivas, emolduradas pela urbanidade e protagonizadas por personagens jovens e bonitos, alinhados com o disposto pela ditadura da beleza. O elogio ao sexo, por sua vez, está expresso no gesto erotizado de um dos personagens retratados. Por fim, temos os dois mitos relacionados ao poder: o mito do poder material, que aparece nos trajes, cenários e objetos de luxo que compõem algumas peças publicitárias, enquanto o poder sexista se manifesta na condição masculina de conquistador exercida pelo homem alfa, na passividade feminina da mulher beta que vai ao seu encontro e, de modo inverso, na postura ativa da mulher alfa contemporânea, que passa a deter também essa forma de poder.

Em Pimenta (Figuras 2C e 4H), última campanha avaliada, a mulher, sem abdicar dos atributos exigidos pela ditadura da beleza, ocupa um papel central, sendo retratada como uma verdadeira mulher alfa na medida em que age como protagonista na maioria das cenas. O elogio ao sexo também marca presença por meio da chamada sugestiva: E se colocar pimenta?, estampada em todas as peças, como também na simbologia de dominação agora exercida pela mulher que monta de modo sensual um touro mecânico. A brasilidade, presente na riqueza de elementos da fauna e da flora brasileiras, é reforçada pela adição de símbolos místicos oriundos de crenças diversas, característica do sincretismo culturalmente praticado pelo povo brasileiro.

\section{Análise sincrônica: a estrutura mitológica constituinte da Chilli Beans}

Partindo do princípio de que a mensagem de uma campanha resulta da contribuição de cada mito reproduzido em suas peças, assumimos que a coexistência desses mitos, motivada pela intenção de construir o sentido maior e integrado da campanha, revela uma conexão entre todos eles. Para levantar as relações existentes, seguindo a lógica sincrônica de simultaneidade, fizemos o cruzamento de cada mito com todos aqueles que coabitavam a mesma campanha. Ao levar em conta todas as aparições de determinado mito durante o período estudado, foi possível mapear toda sorte de vínculo desse com os demais mitos identificados (Figura 5). 


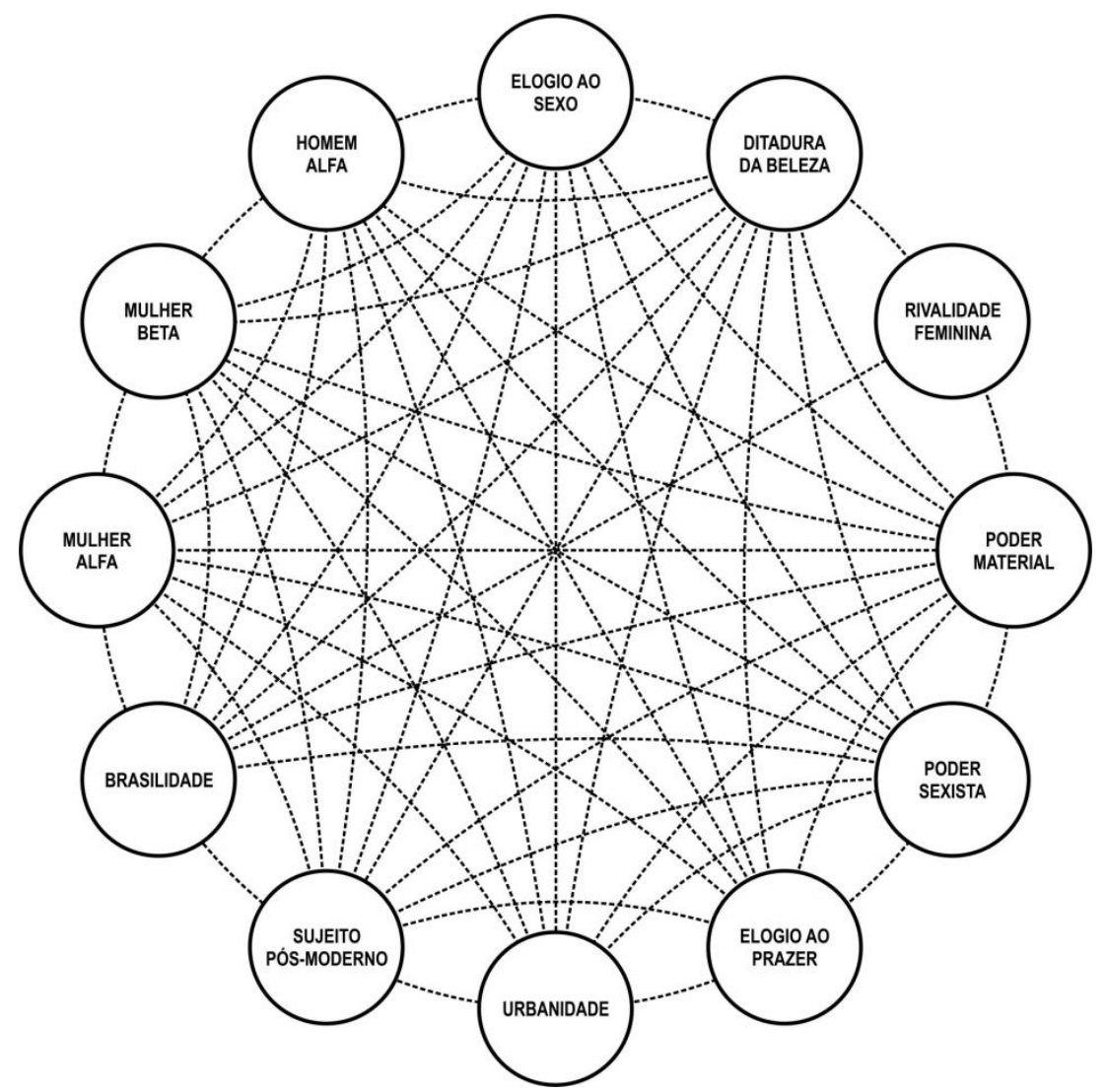

Figura 5. Relações Sincrônicas entre os Mitos da Chilli Beans.

O cruzamento dos doze mitos identificados, combinados um a um entre eles, permitiria um total de 66 relações possíveis. Respeitadas as aparições de cada mito dentro das campanhas, foram levantadas 56 relações. O resultado, portanto, está bem próximo da totalidade possível, o que nos levou a inferir um alto grau de complementaridade entre os mitos e a existência de uma unidade mítica na publicidade desenvolvida pela marca estudada. Estando clara para nós a razão do grande número de conexões identificadas, em vez de tratar dos casos em que há relação entre os mitos, julgamos mais proveitoso abordar as peculiaridades daqueles casos em que não houve vínculo. Das dez relações que não se concretizaram, em oito casos isso não ocorreu por se tratar do mito rivalidade feminina, presente numa única campanha, a qual se combina com apenas três mitos dos onze possíveis (ditadura da beleza, poder material e brasilidade). A justificativa para os outros dois casos em que não houve as relações esperadas liga-se com o mito brasilidade, que, dentro de suas respectivas campanhas, deixa de se vincular a dois dos onze mitos possíveis (urbanidade e elogio ao prazer).

Considerando o teor conceitual dos mitos reproduzidos pela marca e a maneira como os mesmos foram articulados dentro das campanhas, pudemos perceber que o hedonismo se apresenta como uma metanarrativa agregadora de todas as unidades mitológicas identificadas. Por outro lado, por conta da variedade de mitos e das facetas que esses assumem dentro de cada campanha, o hedonismo não assume um caráter uniforme. Identificamos variações da expressão hedônica da marca, classificadas por nós em três dimensões, compostas cada qual por seu conjunto de mitos (Figura 6). 


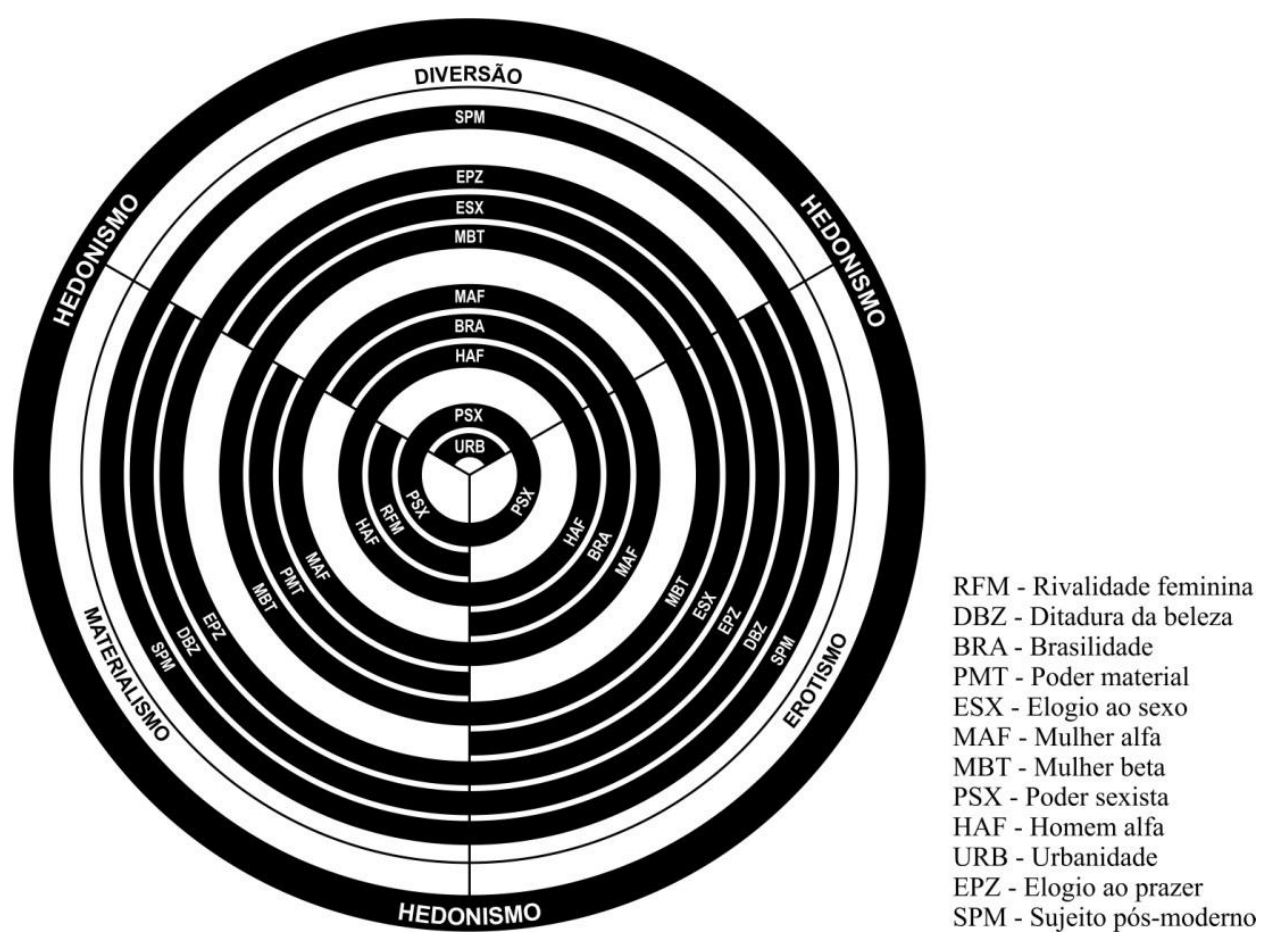

Figura 6. Composição Mítica das Dimensões Hedônicas da Marca Chilli Beans.

Uma das dimensões conceituais do hedonismo é a diversão, que diz respeito a situações que envolvem ludismo e entretenimento, uma faceta contemplada tanto em atividades que remetem à infância (Figura 7C), quanto na prática de jogos numa mesa de bar (Figura 7D). Outra dimensão é o erotismo, que engloba todos os elementos agregados em torno da sugestão sexual (Figura 2). Por fim, o materialismo hedônico está contemplado na satisfação do consumo em si mesmo (Figura 6D), ou no prazer advindo da ostentação de bens como marcadores sociais (Figura 5D). É importante observar que, enquanto alguns mitos estão atrelados exclusivamente a uma das dimensões do hedonismo e outros aparecem localizados dentro de duas delas, metade dos mitos reproduzidos na publicidade da Chilli Beans permeiam as três facetas que compõem o todo conceitual da metanarrativa hedônica.

\section{Será que Dionísio usa Chilli Beans?}

Ao trazer o hedonismo como a grande narrativa que abriga os mitos reproduzidos em sua publicidade, a Chilli Beans aparece alinhada com as grandes mudanças sociais que têm ocorrido nas últimas décadas, todas localizadas no centro das discussões da chamada pós-modernidade (Leão, 2006), que abriga um sujeito fragmentado, carregado de incertezas quanto às garantias que envolvem seu futuro (Fortes, 2009).

De acordo com Maffesoli (2005), a passagem da modernidade para a pós-modernidade trouxe consigo um novo paradigma que marca a substituição da razão e do mito do progresso dos tempos modernos pela importância do prazer e das emoções que renascem com o hedonismo da pósmodernidade. Com essas mudanças, os ideais de progresso do homem, a moral heroica das grandes causas - ideológicas, políticas ou religiosas - e o investimento no futuro perderam a legitimidade entre indivíduos que, agora, enxergam na própria vida uma importância muito maior que as grandes questões da sociedade (Fortes, 2009; Lipovetsky, 2000). Os mitos que sustentam a construção da marca Chilli Beans celebram esse novo momento da sociedade, na medida em que manifestam, por meio do erotismo, da diversão e do materialismo, uma atmosfera marcada pela busca e o exercício do prazer, contextualizada nas mais variadas situações cotidianas. 
De acordo com Maffesoli (2005), na pós-modernidade, Prometeu - o deus do trabalho e da razão - deu lugar a Dionísio ${ }^{(6)}$ - o deus do prazer. A publicidade desenvolvida pela Chilli Beans apostou no universo hedônico desde seu início. Sempre pautada pela intensidade de seus personagens, é possível observar que as situações retratadas pela marca, como oportunidades para se alcançar a felicidade, foram mudando. Se no seu início o erotismo deu o tom às campanhas, os resultados sugerem que, ao longo dos anos, o hedonismo da marca teve suas formas de expressão ampliadas e passou a celebrar o prazer em ambientes festivos, na prática de atividades lúdicas e no incentivo aos excessos, inclusive no consumo.

Nos dias atuais, em que as expectativas se mostram reduzidas pelo futuro, que se tornou incerto, há uma perda da percepção de continuidade da História, do sentimento de pertencimento a gerações sucessivas e do desejo de transmissão das próprias crenças às gerações seguintes (Fortes, 2009). Esse fenômeno justifica o que Maffesoli (2004) chama de presenteísmo, para ele, uma energia hedônica que se representa no presente. Em outras palavras, o sonho do paraíso futuro é substituído pela busca da satisfação imediata, portanto, há um desejo de se viver o presente com a maior intensidade possível, e não viver a expectativa de um futuro de gratificações remotas e compensadoras (Lipovetsky, 2000). Esse espírito carpe diem é compartilhado pela Chilli Beans e aparece de maneira acentuada em algumas campanhas que convidam para uma vida que, não só pode, mas deve ser aproveitada com intensidade.

No contexto contemporâneo, o hedonismo tem uma relação estreita com a sociedade do consumo, para a qual o indivíduo tem o dever de ser feliz e, segundo Baudrillard (2008), há uma ilusão de que esta felicidade passa necessariamente pelo ato de consumir. Como era de se esperar, os óculos de sol marcam presença numa quantidade expressiva das peças publicitárias veiculadas, aproveitando certamente o raciocínio de que o uso do produto, se não garante, certamente contribui para que o indivíduo encontre a tão procurada felicidade.

\section{Considerações Finais}

Seguindo Roland Barthes, a presente pesquisa pôde confirmar que a publicidade, se estudada sob um ponto de vista que vá além do que o signo alcança, revela a existência de narrativas míticas que, na maioria das vezes, passam despercebidas pelos olhares desatentos.

Por esse caminho, nossos achados sugerem que a Chilli Beans busca, de forma recorrente, uma associação com o prazer em suas variadas facetas. Tal intenção se revela desde a simbologia da pimenta - erotismo, malícia, calor e intensidade - e do nome que ilustram sua marca, até o forte apelo ao hedonismo contido em suas mensagens. Por meio dos doze mitos reproduzidos em sua publicidade, a Chilli Beans se faz existir pelo erotismo, o materialismo e a diversão que compõem esse espírito carpe diem pelo que a marca se traduz.

A Chilli Beans é exemplo claro da importância de se estudar as marcas como produções culturais, pois, mais do que chamar a atenção para atributos utilitários ou mesmo emotivos, a sua publicidade constrói seus apelos em cima de narrativas socioculturais que produzem e reproduzem significados que habitam a vida cotidiana.

Entendemos que a presente pesquisa contribua com o conhecimento da área de marketing na medida em que propicia uma lógica diferente das mais usualmente utilizadas para se pesquisar sobre a construção de identidade das marcas. Trata-se de uma abordagem emergente (interpretativa) nas pesquisas em marketing, que, apesar de já ter se estabelecido no campo da pesquisa do consumidor (vide a chamada Consumer Culture Theory), ainda é pouco explorada nos estudos de branding. Por outro lado, a pesquisa contribui para o conhecimento de marcas brasileiras, campo de estudos ainda insipiente. 
Em relação à contribuição prática da pesquisa para as organizações, o estudo sugere como principal implicação gerencial que estas deveriam atentar para a possibilidade de uma publicidade que conte histórias, pois são nestas que residem o mito e seu poder de conquista. Num cenário de crescente competição e imitação das características de produtos e mesmo mensagens veiculadas pelas marcas, a ancoragem conceitual das marcas em mitos poderosos oferece como vantagem tanto a potencialização do vínculo dessas com seus consumidores quanto um traço simbólico menos emulável.

Apesar da riqueza das informações acessadas, reconhecemos como limitação da pesquisa a construção do corpus ter sido baseado apenas na publicidade impressa, deixando de fora os anúncios audiovisuais, que, pela riqueza de detalhes que carregam, muito teriam a contribuir para o estudo do mito. Assumindo que cada campanha guarda em si uma coerência conceitual, entendemos que tal ressalva tenha nos limitado no que se refere à diversidade sígnica das campanhas. Contudo, tendo em vista que esses aspectos perfazem o sistema primeiro da semiologia barthesiana, acreditamos que tal escolha não tenha comprometido a identificação dos mitos que, conservados no sistema segundo, tiveram sua presença assegurada.

É importante sublinhar que o trabalho, ao adotar as campanhas publicitárias como referência analítica, teve o intuito de acessar tão somente a construção da identidade da marca por meio do estudo de seus mitos. Dessa forma, não considerou a visão dos agentes responsáveis pela criação dos mesmos, nem se ateve à sua recepção pelos consumidores.

Diante do exposto, identificamos como possibilidade de futuras pesquisas o estudo de outras marcas a partir da perspectiva que adotamos, uma vez que isso incorreria num campo fértil de conhecimento na área de branding. Por outro lado, entendemos que seria de grande valia a realização de pesquisas que ampliassem o estudo dos mitos para outras duas perspectivas. A primeira delas se debruçaria sobre os mecanismos de produção e reprodução do mito na publicidade, acessando, para isso, a compreensão dos profissionais de criação publicitária sobre tal processo. A outra perspectiva se voltaria para o consumidor, buscando-se um entendimento de como se dá a recepção e a ressignificação do mito por parte deste.

\section{Notas}

\footnotetext{
${ }^{1}$ Trabalho resultante de pesquisa custeada pelo CNPq e pela FACEPE.

${ }^{2} \mathrm{O}$ conceito de mito barthesiano adotado neste trabalho, por extensão, também difere daquele proposto por autores como Randazzo, S. (1996). A criação de mitos na publicidade: como os publicitários usam o poder do mito e do simbolismo para criar marcas de sucesso. Rio de Janeiro: Rocco e Campbell, J. (1990). O poder do mito. São Paulo: Palas Athena.

${ }^{3}$ Partimos das categorias teórico-metodológicas de Roland Barthes. Todavia, as mesmas não se propõem a possibilidades empíricas. Dessa forma, as categorias apresentadas foram classificadas a partir dos dados empíricos analisados.

${ }^{4}$ Dentro da categoria de símbolo, este trabalho não considerou a revitalização no desenho da marca, pois, com exceção das versões adaptadas do logo para campanhas específicas, seus elementos gráficos e simbólicos se conservaram ao longo do tempo. Desde o início, a marca tem mesma tipografia e adota a pimenta como símbolo. Recentemente, esta passou a ter maior proporção em relação ao logotipo, que agora adota uma versão compacta em substituição ao desenho horizontal anterior.

${ }^{5}$ Os autores deste artigo, a despeito de terem formação em nível de pós-graduação em Administração, são graduados em Comunicação Social, tendo sido a Semiologia uma das bases teóricas e metodológicas desta formação.

${ }^{6}$ A referência a Dionísio neste artigo não se baseia na mitologia clássica, mas a esta articulação teórica.
}

\section{Referências}

Aaker, J. L. (1997). Dimensions of brand personality. Journal of Marketing Research, XXXIV(3), 347356. doi: $10.1509 / \mathrm{jmkr} .46 .1 .105$ 
Arnould, E. J., \& Thompson, C. J. (2005). Consumer culture theory (CCT): twenty years of research. Journal of Consumer Research, 31(4), 868-882. doi: 10.1086/426626

Barthes, R. (2006). Elementos de semiologia (17a ed.). São Paulo: Cultrix.

Barthes, R. (2009). Mitologias (4a ed.). Rio de Janeiro: Difel.

Baudrillard, J. (1990). Significação da publicidade. In L. C. Lima (Org.), Teoria da cultura de massa (4a ed., pp. 273-280). Rio de Janeiro: Paz e Terra.

Baudrillard, J. (2008). A sociedade de consumo (3a ed.). Lisboa: Edições 70.

Bauer, M. W., \& Aarts, B. (2008). A construção do corpus de pesquisa: um princípio para a coleta de dados qualitativos. In M. W. Bauer \& G. Gaskell (Orgs.), Pesquisa qualitativa com texto, imagem e som (7a ed., pp. 41-45). Petrópolis: Vozes.

Belk, R. W. (1988). Possessions and the extended self. Journal of Consumer Research, 15(2), 139167.

Bengtsson, A., \& Ostberg, J. (2006). Researching the cultures of brands. In R. W. Belk (Ed.), Handbook of qualitative research methods in marketing (pp. 83-93). Cheltenhan: Edward Elgar.

Brown, S. (1993). Postmodern marketing? European Journal of Marketing, 27(4), 19-34. doi: $10.1108 / 03090569310038094$

Chernatony, L. de, \& McDonald, M. H. B. (2006). From brand vision to brand evaluation. Oxford: Butterworth-Heinemann.

Costa, J. (2008). A imagem da marca: um fenômeno social. São Paulo: Rosari.

Creswell, J. W. (2007). Projeto de pesquisa: métodos qualitativo, quantitativo e misto (2a ed.). Porto Alegre: Artes Médicas.

Featherstone, M. (1995). Cultura de consumo e pós-modernismo. São Paulo: Studio Nobel.

Fortes, I. (2009). A psicanálise face ao hedonismo contemporâneo. Revista Mal-estar e Subjetividade, IX(4), 1123-1144.

Fournier, S. (1998). Consumers and their brands: developing relationship theory in consumer research. Journal of Consumer Research, 24(4), 343-373. doi: 10.1086/209515

Fracta Propaganda e Marketing. (1998). Campanha Ciúmes. São Paulo: Autor.

Fracta Propaganda e Marketing. (2000). Campanha Peladas. São Paulo: Autor.

Fracta Propaganda e Marketing. (2002). Campanha Fetiche. São Paulo: Autor.

Fracta Propaganda e Marketing. (2003). Campanha Olhos. São Paulo: Autor.

Fracta Propaganda e Marketing. (2005). Campanha Pornochanchada. São Paulo: Autor.

Fracta Propaganda e Marketing. (2006). Campanha Relógios. São Paulo: Autor.

Fracta Propaganda e Marketing. (2007). Campanha Special. São Paulo: Autor.

Fracta Propaganda e Marketing. (2008). Campanha Compulsão. São Paulo: Autor.

Fracta Propaganda e Marketing. (2009c). Campanha Novos Mundos - Gasoline. São Paulo: Autor.

Fracta Propaganda e Marketing. (2009b). Campanha Novos Mundos - Play. São Paulo: Autor. 
Fracta Propaganda e Marketing. (2009a). Campanha Novos Mundos - Royale. São Paulo: Autor.

Fracta Propaganda e Marketing. (2010). Campanha Pimenta. São Paulo: Autor.

Gaião, B. F. S., Souza, I. L., \& Leão, A. L. M. S. (2012). Consumer Culture Theory (CCT) já é uma escola de pensamento em marketing? Revista de Administração de Empresas, 52(3), 330-344. doi: $10.1590 / \mathrm{S} 0034-75902012000300005$

Holt, D. B. (1995). How consumers consume: a typology of consumption practices. Journal of Consumer Research, 22(1), 1-16.

Holt, D. B. (2002). Why do brands cause trouble? A dialectical theory of consumer culture and branding. Journal of Consumer Research, 29(1), 70-90. doi: 10.1086/339922

Holt, D. B. (2005). Como as marcas se tornam ícones: os princípios do branding cultural. São Paulo: Cultrix.

Leão, A. L. M. S. (2006, setembro). Hedonismo como valor do cliente pós-moderno: simples clímax experiencial ou uma nova razão no consumo? Anais do Encontro Nacional da Associação Nacional de Pós-Graduação e Pesquisa em Administração, Salvador, BA, Brasil, 30.

Leão, A. L. M. S., \& Mello, S. C. B. (2009). Atividades marcárias na vida cotidiana dos consumidores: descoberta de uma nova forma de se pensar as marcas? Revista de Administração Contemporânea, 13(1), 92-116. Recuperado de http://www.scielo.br/pdf/rac/v13n1/a07v13n1.pdf. doi: 10.1590/S1415-65552009000100007

Leão, A. L. M. S., Mello, S. C. B., \& Vieira, R. S. G. (2009). O papel da teoria no método de pesquisa em Administração. Revista Organizações em Contexto, 5(10), 1-16.

Lipovetsky, G. (2000). Sedução, publicidade e pós-modernidade. Revista FAMECOS, (12), 7-13.

Maffesoli, M. (2004). A parte do diabo. Rio de Janeiro: Record.

Maffesoli, M. (2005). Sombra de Dionísio. Porto Alegre: Zouk.

McCracken, G. (2003). Cultura e consumo: novas abordagens ao caráter simbólico dos bens e das atividades de consumo. Rio de Janeiro: Mauad.

McCracken, G. (2005). Culture and consumption II: markets, meaning, and brand management. Bloomington: Indiana.

Merriam, S. B. (1998). Qualitative research and case study applications in education: revised and expanded from case study research in education (2nd ed.). San Francisco: Jossey-Bass Education Series and The Josey-Bass Higher Education Series.

Mick, D. G., \& Oswald, L. R. (2006). The semiotic paradigm on meaning in the marketplace. In R. W. Belk (Ed.), Handbook of qualitative research methods in marketing (pp. 31-45). Cheltenham: Edward Elgar.

Nairn, A., Griffin, C., \& Wicks, P. G. (2008). Children's use of brand symbolism. European Journal of Marketing, 42(5/6), 627-640. doi: 10.1108/03090560810862543

Neumeier, M. (2008). The brand gap - o abismo da marca: como construir a ponte entre a estratégia e o design (2a ed.). Porto Alegre: Bookman.

Paiva, F. G., Jr., Leão, A. L. M. S., \& Mello, S. C. B. (2011). Validade e confiabilidade na pesquisa qualitativa em Administração. Revista de Ciências da Administração, 13(31), 190-209. doi: $10.5007 / 2175-8077.2011 v 13 n 31 \mathrm{p} 190$ 
Penn, G. (2002). Análise semiótica de imagens paradas. In M. W. Bauer \& G. Gaskell (Eds.), Pesquisa qualitativa com texto, imagem e som (3a ed., pp. 319-342). Petrópolis: Vozes.

Rocha, E. (2008). O que é mito. São Paulo: Brasiliense.

Saussure, F. (2006). Curso de linguística geral. São Paulo: Cultrix.

Schroeder, J. E. (2009). The cultural codes of branding. Marketing Theory, 9(1), 123-126. doi: $10.1177 / 1470593108100067$

Scott, T., Stanford, N., \& Thompson, D. R. (2004). Killing me softly: myth in pharmaceutical advertising. British Medical Journal, 329(7480), 1484-1488. doi: 10.1136/bmj.329.7480.1484

Semprini, A. (2010). A marca pós-moderna: poder e fragilidade da marca na sociedade contemporânea (2a ed.). São Paulo: Estação das Letras e Cores.

Sherry, J., \& Camargo, E. (1987). May your life be marvelous: English language labeling and the semiotics of Japanese promotion. Journal of Consumer Research, 14(2), 174-188.

Silva, D. R., \& Mello, S. C. B. (2010). A mitologia na representação cultural da cachaça: imagem negativa e tentativa de ressignificação. E-Compós, 13(1), 1-14.

Simmons, G. (2008). Marketing to postmodern consumers: introducing the internet chameleon. European Journal of Marketing, 42(3/4), 299-310. doi: 10.1108/03090560810852940

Slater, D. (2002). Cultura do consumo e modernidade. São Paulo: Nobel.

Zhao, X., \& Belk, R. K. (2008). Politicizing consumer culture: advertising's appropriation of political ideology in China's social transition. Journal of Consumer Research, 35(2), 231-244. doi: 10.1086/588747 